\title{
Thermoluminescence study of aluminium oxide doped germanium prepared by combustion synthesis method
}

\author{
Nurul Syazlin Binti Saharin*, Nor Ezzaty Ahmad, Abdul Rahman Tamuri, \\ Department of Physics, Faculty of Science, Universiti Teknologi Malaysia, 81310 UTM Johor Bahru, \\ Johor, Malaysia.
}

\begin{abstract}
The present paper reports the optimum concentration of germanium $(\mathrm{Ge})$ dopant in aluminium oxide $\left(\mathrm{Al}_{2} \mathrm{O}_{3}\right)$ samples prepared by combustion synthesis (CS) method for thermoluminescence (TL) studies. The samples were prepared at various Ge concentration i.e. 1 to $5 \% \mathrm{~mol}$. The phase formation of un-doped and Ge-doped $\mathrm{Al}_{2} \mathrm{O}_{3}$ samples was determined using X-ray Diffraction (XRD). The sharp peaks present in the XRD pattern confirms the crystallinity of the samples. The samples were then exposed to 50 Gy Cobalt-60 sources (Gamma cell 220). TL glow curves were measured and recorded using a Harshaw Model 3500 TLD reader. Comparison of TL peaks were observed to obtain the best composition of Ge dopants. A simple glow curves TL peak at around $175^{\circ} \mathrm{C}$ for all composition samples was observed. It was also found that the composition of aluminium oxide doped with $3.0 \%$ of germanium exhibits the highest thermoluminescence (TL) intensity which is 349747.04 (a.u).
\end{abstract}

Keywords: Thermoluminescence; germanium doping; combustion synthesis

\section{Introduction}

The application of thermoluminescence (TL) dosimetry in radiation protection has grown steadily due to the worldwide progress of the development of solid thermoluminescent dosimeter (TLD). Various kinds of thermoluminescence (TL) dosimeters have been used in radiation dosimetry. One of the materials that can be considered for TLD was aluminium oxide. This is due to aluminium oxide $\left(\alpha-\mathrm{Al}_{2} \mathrm{O}_{3}\right)$ shows an effective number close to that of bone $\left(Z_{\text {eff }}=11.28\right)$, it becomes a better choice to be used in medical and environmental dosimetry (Bos, 2001). The TL properties of $\mathrm{Al}_{2} \mathrm{O}_{3}$ samples of different dopants materials which can enhance TL properties have been studied by several researches for nearly 50 years $[1,2]$

\footnotetext{
*Corresponding author: syazlin3@gmail.com
} 
The materials were generally synthesized by sol-gel method [3], ion beam implantation [4], solvent evaporation [5] and combustion synthesis (CS) [6,7,8]. Among this method, combustion synthesis (CS) is an effective and low-cost method for production of various industrially useful materials $[9,10]$. The solution preparation only requires low processing temperatures and short reaction times ( $\sim$ seconds) making it a quick and easy process $[11,12,13]$. This process is used directly in the production of high purity and homogeneous ceramic oxide powders. The combustion process is due to an exothermic, redox reaction between nitrate ions and fuel. The large volume of gases released during the reaction promotes a rapid disintegration of the precursor gel, yielding the desired nanocrystalline materials [14].

The presence of impurities in a material is important to the thermoluminescence process. Recently, to have a better performance in the dosimetric purpose, $\mathrm{Al}_{2} \mathrm{O}_{3}$ is always doped with impurities that induce many different types of trapping centers at which charged particles produce ionizing radiation [15]. Since then, there are a lot of efforts have been directed towards the improvements on its sensitivity via various dopants such as $\mathrm{Si}, \mathrm{Ti}$, [16], Mg and Y [17], Cr and Ni [18]. Study by Ravichandran., (2014) [19] of undoped and $(2-10 \mathrm{~mol} \%) \mathrm{Al}$ doped $\mathrm{ZrO}_{2}$ nano powder were synthesized using solution combustion method having glycine as a fuel which is pre-heated at approximately $500^{\circ} \mathrm{C}$. However, the study only concerned on the optical properties of the samples and not on the thermoluminescence properties. Barros et al, (2008), reported the highest sensitivity were found for $\mathrm{Al}_{2} \mathrm{O}_{3}$ samples doped with $5 \% \mathrm{~Tb}, 5 \% \mathrm{Eu}$, and 5\% Si. The samples were exposed to $1.5 \mathrm{~Gy} \mathrm{Co}-60$ gamma rays. It stated that the TL response were 5000 times higher than the un-doped $\mathrm{Al}_{2} \mathrm{O}_{3}$. They also reported that a well defined glow curve peaks was observed at approximately $200^{\circ} \mathrm{C}$ which is well suited for radiation dosimetry.

However, thermolumiescence properties of $\mathrm{Ge}$ doped $\mathrm{Al}_{2} \mathrm{O}_{3}$ prepared by CS method have not been reported so far. Recently, interest of Ge as doped for dosimetric purpose has increased based from previous study Ge doped optical fibre as a thermoluminescence dosimeter in radiotherapy is a promising material because it gives good response and full fill the criteria of thermoluminescence properties [20]. However, the preparation of optical fibre is not simple as CS technique [21]. Hence, the aim of this present study is to prepare undoped and germanium doped aluminium oxide $\left(\mathrm{Al}_{2} \mathrm{O}_{3}\right.$ : Ge) nanocryatalline powder synthesis by CS method at various concentrations (1-5mol\%). The optimum Ge concentration is chosen for TL study.

\section{Materials and methods}

$\mathrm{Al}_{2} \mathrm{O}_{3}$ doped with Germanium was synthesized using the combustion synthesis method. The samples were prepared using aluminium nitrate $\left(\mathrm{Al}\left(\mathrm{NO}_{3}\right)_{3} .9 \mathrm{H}_{2} \mathrm{O}\right)$ as an oxidizer and urea $\left(\mathrm{CH}_{4} \mathrm{~N}_{2} \mathrm{O}, 98 \%\right)$ as a fuel, by Sigma Aldrich and Germanium dopant were added with concentration between 1 to $5 \mathrm{~mol} \%$. Urea is suitable fuels because they are amino acid that can act as complexings agent of the metal ion in the solution and also serves as fuel to the synthesis nanocrystalline metal oxides. The starting materials taken by mixing $15 \mathrm{~g}$ of aluminium nitrate, $\mathrm{Al}\left(\mathrm{NO}_{3}\right)_{3}, 6 \mathrm{~g}$ of urea, $\mathrm{CO}\left(\mathrm{NH}_{2}\right)_{2}$ and different weight dopant concentration from $1 \%$ to $5 \%$. Then, $20 \mathrm{~mL}$ distilled water was added to the samples and stirred for 15 minutes using magnetic stirrer in order to obtain a homogeneous solution for completely dissolved. Then the solution was poured into alumina crucible and transferred to muffle-furnace pre-heated at $500^{\circ} \mathrm{C}$. The sample ignited spontaneously with few seconds and produced white foamy product. The sample were then taken out from the mufflefurnace and allowed to cool down before grinding using mortar. X- Ray diffractometer (XRD) was used to identify the crystalline phase of the samples. Before the samples were 
exposed to gamma radiation pre-annealing process were carried out. This procedure was done to remove any effects due to any unwanted previous irradiation without damaging the material. The powders were annealed at $400^{\circ} \mathrm{C}$ for $1 \mathrm{~h}$ followed by cooling process at $80^{\circ} \mathrm{C}$ for $16 \mathrm{~h}$ [22]. The prepared samples were then irradiated at 50 Gy sources of Cobalt-60 gamma Cell Model 220 Excel at Universiti Kebangsaan Malaysia, Bangi, Malaysia. The TL response from the glow curve was measured using a TLD reader Harshaw Model 3500 with optical detection of light with wavelength between 400 and $430 \mathrm{~nm}$.

\section{Results and discussion}

\subsection{X-Ray Analysis (XRD)}

Figure 1 represents the XRD pattern of the as synthesized $\mathrm{Al}_{2} \mathrm{O}_{3}$ and $\mathrm{Al}_{2} \mathrm{O}_{3}$ doped with germanium at $3 \%$ mol concentration. XRD was done to confirm the phase of the sample either amorphous or crystalline. The diffraction pattern depicted intense peaks thereby, gives a strong indication that the prepared sample has high degree of crystallinity. The peaks found match with the International Centre for Diffraction Data (ICDD) which are $\mathrm{Al}_{2} \mathrm{O}_{3}$ (01-070-5679) and $\mathrm{Al}_{2} \mathrm{O}_{3}$ : Ge (01-088-2013). Pure $\mathrm{Al}_{2} \mathrm{O}_{3}$ sample was observed and no other impurity phase was detected. It is to be noted that small amounts of dopants do not produce significant effect on the basic crystal structure of $\mathrm{Al}_{2} \mathrm{O}_{3}$. The addition of dopant will not change the unit cell parameters must not change [23].

\subsection{TL intensity}

Figure 2 represents the TL intensity of $\mathrm{Al}_{2} \mathrm{O}_{3}$ : Ge with different concentration ( 1 to $5 \mathrm{~mol} \%$ ). In the same Figure, the standard deviations are also plotted against the doped concentration. The TL intensity of the sample was found to vary with increasing Ge concentration. The TL intensity increase from $1 \mathrm{~mol} \%$ Ge to maximum intensity at $3 \mathrm{~mol} \%$ Ge concentration 349747.04 (a.u). Then the intensity decreases with further increase of Ge concentration. This may be due beyond $3 \mathrm{~mol} \%$ concentration, quenching is bound to occur hence the optimum concentration for Ge only suite for this concentration. Highest TL intensity at $3 \mathrm{~mol} \%$ Ge is attributed to the recombination of the excited electrons from the valences band with defects produced via irradiation [24]. As a conclusion, it is found that the optimum concentration value of Ge dopants is at $3 \mathrm{~mol} \%$ with very low standard error. 


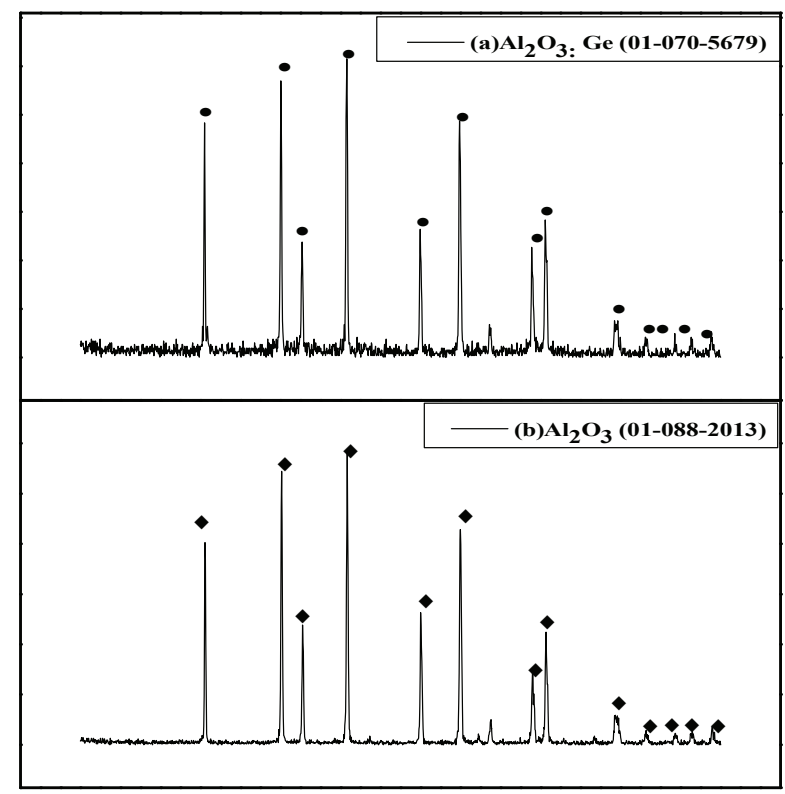

Fig1. XRD pattern of (a) $\mathrm{Al}_{2} \mathrm{O}_{3}$ doped 3 mol \% Ge samples and (b) un-doped $\mathrm{Al}_{2} \mathrm{O}_{3}$

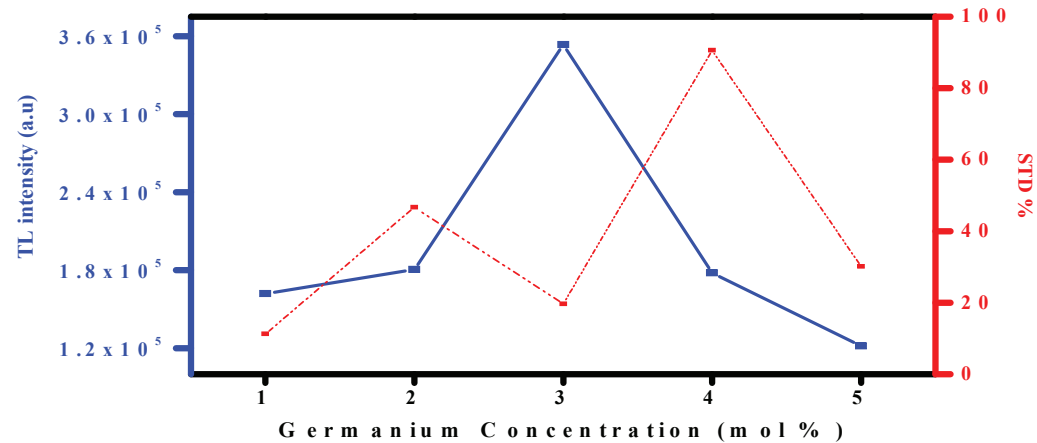

Fig2. TL intensity and standard error of $\mathrm{Al}_{2} \mathrm{O}_{3}$ : Ge with different concentration 


\subsection{TL Glow curve}

Figure 3 displays the glow curve of $\mathrm{Al}_{2} \mathrm{O}_{3}$ doped with $\mathrm{Ge}$ sample at different concentration of germanium. Two peaks are observed, one prominent peak at around $175^{\circ} \mathrm{C}$ and another hump at around $230{ }^{\circ} \mathrm{C}$. From the Figure 4, it is observed that the intensity of TL peaks increases with the increase in Ge composition where the highest peak found is for $3 \mathrm{~mol} \%$ Ge concentration. The result is similar with the work reported by Barros et al. (2008) for $\mathrm{Al}_{2} \mathrm{O}_{3}$ prepared by CS method as mention before. The results also agree with the work done for $\mathrm{Al}_{2} \mathrm{O}_{3}$ doped with $\mathrm{Tb}^{3+}$ and $\mathrm{Tm}^{3+}$ where the $\mathrm{Tl}$ glow curve peak was observed at $220^{\circ} \mathrm{C}$ with a linear response in the dose range of 0.1-1 Gy prepared by same method [25]. Study by J.V.Soares, 2014, [26] showed an intense peak at $\sim 190^{\circ} \mathrm{C}$ and two other with low intensity at $290^{\circ} \mathrm{C}$ and $350^{\circ} \mathrm{C}$. Hence, based from this of the presence of germanium dopants in $\mathrm{Al}_{2} \mathrm{O}_{3}$ sample enhanced the TL response and this will full fill the major tools to decide on the TL dosimetry potential of the material. The glow curves are particularly important since they are the main indicators of whether a material can be used for TL dosimeter purposes or not. According from Pekpak, 2010, [27] to obtain a good glow curve, a single peak was normally found at approximately $200^{\circ} \mathrm{C}$ temperature. Peak at low temperature (approximately of $100^{\circ} \mathrm{C}$ ) at below will normally fade quickly and could not yield any information about radiation content.

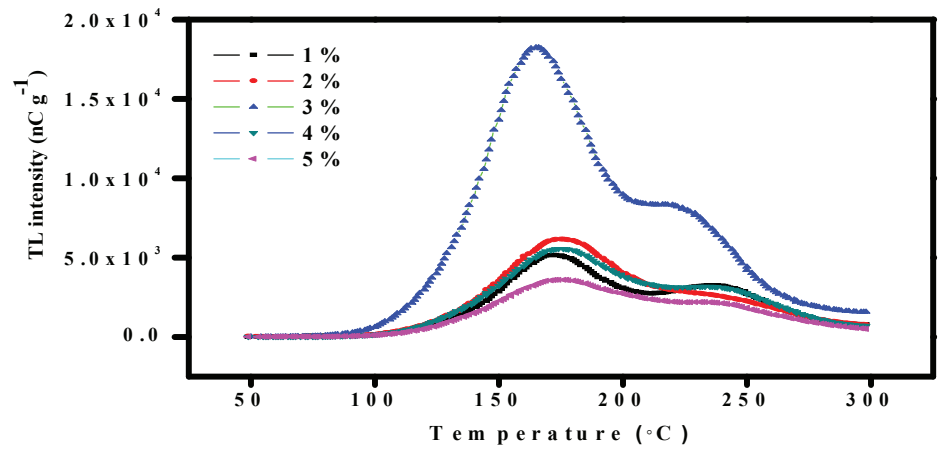

Fig3. TL glow curve of $\mathrm{Al}_{2} \mathrm{O}_{3}$ : Ge at different mole concentration exposed to $50 \mathrm{~Gy}$ Cobalt-60

\section{Conclusion}

From the results above it is possible to conclude that CS method is very suitable for the preparation of $\mathrm{Al}_{2} \mathrm{O}_{3}$ doped $\mathrm{Ge}$ for dosimetric applications. The technique is fast, low cost and produces well defined materials that can be used for dosimetric applications. The concentration analysis shows that the Ge concentration that optimizes the TL response is at $3.0 \mathrm{~mol} \%$ which has highest TL intensity which is 349747.04 (a.u). The crystallinity of the samples is proven by the XRD sharp peaks. Based from the TL intensity and TL glow curve figure, it can be concluded that the best Ge concentration as $\mathrm{Al}_{2} \mathrm{O}_{3}$ dopants is $3 \mathrm{~mol} \%$ where it provides high TL intensity response with low standard error compare other concentration. This value can be used to further study the TL properties. 


\section{Acknowledgement}

The authors would like to thank the Ministry of Education (MOE) of Malaysia for the financial support (Vote Number: 10H20) and Universiti Kebangsaan Malaysia for providing irradiation source of Cobalt-60 gamma Cell Model 220 Excel and Universiti Teknologi Malaysia for providing research facilities

\section{References}

[1] J.F.S., Bitencourt, S.H., Tatumi, Synthesis and thermoluminescence properties of $\mathrm{Mg}^{2+}$ doped nano structured aluminium oxide. Phys. Procedia 2, 501-514, (2010).

[2] J. K. Rieke, and J. Daniels, Thermoluminescence Studies of Aluminium Oxide. $J$. Phys. Chem. 61(5), 629-633, (1957).

[3] A.A. Kaplyankii, A.B. Kulinkin, A.B. Kutsenko, S.P. Feofilov, R.I. Zakharchenya, T.N. Vasilevskaya, Optical spectra of triply-charged rare-earth ions in polycrystalline corundum. Phys. Sol. State, 40, 1310-1316, (1998).

[4] N. Can, P.D. Townsend, and D.E. Hole, Enhancement of luminescence by pulse laser annealing of ion-implanted europium in sapphire and silica. J. Appl. Phys.78, 67376744, (1995).

[5] J. Azorin, Preparation methods of thermoluminescent materials for dosimetric applications: An overview. Appl. Radiat. Isot. 83, 187-191, (2002).

[6] D.V, Barros, S.M. de Azevedo Walter, M. Khoury and Pedro Linhares Filho, Combustion synthesis: A suitable method to prepare $\mathrm{Al}_{2} \mathrm{O}_{3}$ doped materials for thermoluminescent dosimetry. Radiat. Meas. 43, 345-348, (2008).

[7] G. Hirata, N. Peres, M. Tajeda, J.A. Gonzalez-Ortega, and J. McKittrick, Luminescence study in Eu-doped aluminium oxide phosphors. Opt. Mater. 27,1311$1315,(2005)$.

[8] V.SM. Barros, W.M.de Azevedo, H.J. Khoury, M.E. A. Andrade, and P. Linhares Filho, Thermoluminescence study of aluminium oxide doped with terbium and thulium. Radiat. Meas. 45,435-437. (2010).

[9] B.N. Lakshminarasappa, J.R. Jayaramaiah, \& B.M. Nagabhushana, Thermoluminescence of combustion synthesized yttrium oxide, Powder Technol. 217, 7-10, (2012).

[10] A. Sharma, A. Rani, A. Singh, O.P. Modi, \& G.K. Gupta, Synthesis of alumina powder by the urea-glycine-nitrate combustion process: a mixed fuel approach to nanoscale metal oxides, Appl Nanosci. 4(3), 315-323, (2014).

[11] R.K. Lenka, T. Mahata, P.K. Sinha, \& A.K Tyagi, Combustion synthesis of gadoliniadoped ceria using glycine and urea fuels, J. Alloys Compd. 466, 326-329. (2008).

[12] R. Garcia, and G.A. Hirata, New combustion synthesis technique for the production of $\left(\operatorname{In}_{\mathrm{x}} \mathrm{Ga}_{1}-\mathrm{x}\right)_{2} \mathrm{O}_{3}$ powders: Hydrazine/metal nitrate method, 16,1059-1065, (2001).

[13]B.N. Lakshminarasappa, J.R. Jayaramaiah, \& B.M. Nagabhushana, Thermoluminescence of combustion synthesized yttrium oxide, Powder Technol. 217, $7-10,(2012)$.

[14] M.C. Gardey Merino, G.E. Lascalea, L.M. Sánchez, P.G. Vázquez, E.D. Cabanillas, \& D.G. Lamas, Nanostructured aluminium oxide powders obtained by aspartic acidnitrate gel-combustion routes, J. Alloys Compd. 495(2),578-582, (2010).

[15] L.C. Yong, H. Wagiran, A.K. Ismail. Thermoluminescence Performance of Carbondoped Aluminium Oxide for Dose Measurement by Various Preparation Methods, Jurnal Teknologi. 62:3, 109-113, (2013). 
[16] Mehta, S.K., Sengupta, S.,b. $\mathrm{Al}_{2} \mathrm{O}_{3}$ phosphor for Thermoluminescence dosimetry. Health Phys. 31, 176-177. (1976)

[17] Osvay. Ma.,Tamas BIRO.,1980. Aluminium oxide in TL Dosimetry. Nucl. Instr. Meth, 175, 60-61.

[18] Lapraz, D., P. Iacconi, D. Daviller, and B. Guilhot. 1991. Thermostimulated Luminescence and Fluorescence of Alpha- $\mathrm{Al}_{2} \mathrm{O}_{3}: \mathrm{Cr}^{3+}$ Samples (Ruby). Phys. Status Solid (A). 126, 521-531.

[19] Ravichandran, A.T., Catherine, K., Pushpa, S., Ravichandran, K., Karthika, K., Nagabhushana, B.M., Mantha, S., and Swaminathan, K. (2014). Effect of Al doping on the structural and optical properties of $\mathrm{ZrO}_{2}$ nanopowders synthesized using solution combustion method. Superlattices and Microstructures.75, 533-542.

[20] N.M. Noor, M. Hussein, T. Kadni, D.A. Bradley, A. Nisbet, Characterizationof Gedoped optical fibres for MV radiotherapydosimetry.Radiat.Phys.Chem.98, 33-4, (2014).

[21] C. L. Ong., S., Kandaiya, H. T., Kho\& M. T. Chong, Segments of a commercial Gedoped optical fiber as a thermoluminescent dosimeter in radiotherapy. Radiation Measurements. 44, 158-162, (2009)

[22] F.O. Ogundare, S.A. Ogundele, M.L. Chithambo, \& M.K. Fasasi, Thermoluminescence characteristics of the main glow peak in a $-\mathrm{Al}_{2} \mathrm{O}_{3}: \mathrm{C}$ exposed to low environmental-like radiation doses, J. Lumin. 139, 143-148, (2013).

[23]S. A.,Pardhi, Nair, G. B., R.,Sharma, \& S. J.Dhoble, Investigation of thermoluminescence and electron-vibrational interaction parameters in SrAl 2 O 4 :Eu $2+$, Dy 3+ phosphors. Journal of Luminescence, 187, 492-498. (2017).

[24] S. P Puppalwar, S. J Dhoble, N. S Dhoble, \& A. Kumar, Nuclear Instruments and Methods in Physics Research B Luminescence characteristics of Li 2 NaBF 6: Cu phosphor, 274, 167-171, (2012).

[25] M.E.A. Andrade, W.M. Azevedo, V.S.M. Barros, \& H.J. Khoury, Thermoluminescence of aluminum oxide co-doped with terbium and thulium obtained via combustion synthesis, Radiat. Meas. 46(12), 1474-1476, (2011).

[26] J.V. Soares, C.F. Gugliotti, Y.S. Kawashima, S.H. Tatumi, \& J.C.R. Mittani, Thermoluminescence and optically stimulated luminescence characteristics of $\mathrm{Al}_{2} \mathrm{O}_{3}$ doped with Tb, Radiat. Meas. 71, 78-80, (2014).

[27] E., Pekpak, A., Yilmaz, and G., Ozbayoglu, An Overview on Preparation and thermoluminescence Characterization of Lithium Borates for Dosimetric Use. The Open Mineral Processing Journal. 3, 14-24, (2010). 